\title{
Enhanced recovery after surgery (ERAS) program for lumbar spine fusion
}

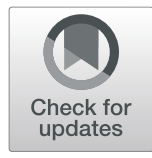

Justin Smith ${ }^{1 *}$ D, Stephen Probst ${ }^{1}$, Colleen Calandra ${ }^{2}$, Raphael Davis ${ }^{2}$, Kentaro Sugimoto $^{1}$, Lizhou Nie ${ }^{3}$, Tong J. Gan ${ }^{1}$ and Elliott Bennett-Guerrero ${ }^{1}$

\begin{abstract}
Background: There is a paucity of literature regarding the implementation of enhanced recovery after surgery (ERAS) protocols for open lumbar spine fusions. We implemented an ERAS program for 1-2-level lumbar spine fusion surgery and identified areas that might benefit from perioperative interventions to improve patient satisfaction and outcomes.

Methods: This institutionally approved quality improvement (QI) ERAS program for lumbar spine fusion was designed for all neurosurgical patients 18 years and older scheduled for 1 or 2 level primary lumbar fusions. The ERAS bundle contained elements such as multimodal analgesia including preoperative oral acetaminophen and gabapentin, postoperative early mobilization and physical therapy, and a prophylactic multimodal antiemetic regimen to decrease postoperative nausea and vomiting. No fluid management or hemodynamic parameters were included. Pre-ERAS and post-ERAS data were compared with regard to potential confounders, compliance with the ERAS bundle, and postoperative outcomes.
\end{abstract}

Results: A total of 230 patients were included from October 2013 to May 2017. The pre-ERAS phase consisted of 123 patients, 11 patients during the transition period, and 96 serving as post-ERAS patients. The pre-ERAS and post-ERAS groups had comparable demographics and comorbidities. Compliance with preoperative and intraoperative medication interventions was relatively good $(\sim 80 \%)$. Compliance with postoperative elements such as early physical therapy, early mobilization, and early removal of the urinary catheter was poor with no significant improvement in post-ERAS patients. There was no significant change in the amount of short-acting opioids used, but there was a decrease in the use of long-acting opioids in the post-ERAS phase (14.6 to $5.2 \%, p=0.025$ ). Post-ERAS patients required fewer rescue antiemetic medications in the recovery room compared to pre-ERAS patients (40 to $24 \%$ ). There was no significant difference in postoperative pain scores or hospital length of stay between the two groups.

Conclusions: Implementing an ERAS bundle for 1-2-level lumbar fusion had minimal effect in decreasing length of stay, but a significant decrease in postoperative opioid and rescue antiemetic use. This ERAS bundle showed mixed results likely secondary to poor ERAS protocol compliance. Going forward, this QI project will look to improve postoperative ERAS implementation to improve patient outcomes.

Keywords: ERAS, Lumbar fusion, Ql spine, Spine surgery

\footnotetext{
* Correspondence: justinksmithmd@gmail.com

${ }^{1}$ Department of Anesthesiology, Stony Brook University Medical Center, 101

Nicolls Rd, Stony Brook, NY 11794, USA

Full list of author information is available at the end of the article
}

(c) The Author(s). 2019 Open Access This article is distributed under the terms of the Creative Commons Attribution 4.0 International License (http://creativecommons.org/licenses/by/4.0/), which permits unrestricted use, distribution, and reproduction in any medium, provided you give appropriate credit to the original author(s) and the source, provide a link to the Creative Commons license, and indicate if changes were made. The Creative Commons Public Domain Dedication waiver (http://creativecommons.org/publicdomain/zero/1.0/) applies to the data made available in this article, unless otherwise stated. 


\section{Introduction}

Back pain and spinal disorders are one of the most commonly encountered medical problems facing the healthcare system. Approximately two thirds of the population will suffer from low back pain (LBP) at some point in their lifetime, and it is estimated that the USA spends over $\$ 100$ billion annually in direct and indirect costs related to LBP (Deyo and Weinstein 2001; Dagenais et al. 2008). A lumbar spinal fusion may improve LBP and help many improve their quality of life. While outcomes after spinal fusion are generally good, many patients experience adverse events such as superficial and deep wound infections, deep vein thrombosis, pseudarthrosis, urinary tract infections, transient ischemic attacks, and continued pain following surgery (Proietti et al. 2013).

In recent years, "fast track" surgery or enhanced recovery bundles have been developed in many surgical specialties to decrease hospital length of stay (LOS) and decrease perioperative morbidity. Kehlet first introduced the enhanced recovery model in 1997 as a multimodal, evidence-based plan to improve patient care in the perioperative period (Kehlet 1997). Since then, many ERAS strategies have shown the effectiveness of enhanced recovery bundles in improving patient outcomes. These ERAS bundles have been used successfully in colorectal surgery, radical cystectomies, major pelvic surgery, and pancreaticoduodenectomies to name a few (Gustafsson et al. 2013; Daneshmand et al. 2014; Nygren et al. 2013; Lassen et al. 2013). To date, there have been very few reports of the implementation of ERAS bundles that focused on improving patient outcomes in open lumbar fusions and spinal surgery (Wainwright et al. 2016; Blackburn et al. 2016). In this study, we hypothesized that the ERAS protocol would decrease: case cancelations, postoperative nausea and vomiting (PONV), length of stay, postoperative pain, and postoperative narcotic use.

\section{Methods}

\section{ERAS protocol development and implementation}

This ERAS QI protocol was implemented at Stony Brook University Hospital in Stony Brook, New York, after receiving institutional approval. The program included neurosurgical patients 18 years and older planned to undergo a 1 or 2 level lumbar spinal fusion. This QI project excluded patients who were pregnant, age $<18$, or planned for a revision of a previous fusion.

The departments of neuroanesthesia and neurosurgery at our institution worked together to review neurosurgery spinal fusion cases to identify interventions that would address unmet postoperative patient care goals. The protocol was divided into preoperative, intraoperative, and postoperative interventions. While some of the bundle elements were already common practice for lumbar fusion procedures at our institution and were included in the ERAS protocol, there was no standardized care bundle for all lumbar fusion patients. Table 1 outlines the protocol.

Among the gaps of the existing care protocol, patient communication was observed to be an important issue to address since some patients were receiving inconsistent recommendations concerning medications to be taken on the day of surgery, and expectations following surgery varied between patients. It was also found that patients with chronic pain were not identified prior to surgery, and there was a need for better pain management postoperatively for all patients. Earlier involvement of physical therapy and social work was another area for improvement to decrease delays in mobilization and discharge. To address these issues, our goals included: improving preoperative patient education, decreasing case cancelations, decreasing hospital LOS, decreasing PONV, decreasing postoperative pain, and decreasing postoperative opioid use.

To improve patient communication, a standardized education packet was given to patients in the neurosurgical clinic prior to surgery. This included information about the surgery, expectations, support services, management of diabetes, and smoking cessation among other things. To decrease case cancelations, the neurosurgery office administrative staff had an increased role in communicating with the surgeon and operating room staff to ensure proper scheduling of cases and to notify care providers of the need to adhere to the ERAS protocol. At preoperative services, education was reinforced and patients underwent a laboratory workup, history and physical prior to surgery. As a means to decrease PONV, all patients were scheduled to receive dexamethasone $8 \mathrm{mg}$ IV after induction of anesthesia, and for patients with more than 2 risk factors (Apfel et al. 2012), oral aprepitant $40 \mathrm{mg}$ was added in the preoperative holding area. Patients were routinely given intraoperative ondansetron $4 \mathrm{mg}$ IV for PONV prophylaxis. The protocol did not include intraoperative fluid or hemodynamic parameters. To decrease postoperative pain and opioid use, a multimodal analgesia regimen was included (Mathiesen et al. 2013). On the day of surgery, the patient was reassessed by the anesthesia care provider and given acetaminophen $975 \mathrm{mg}$ PO and gabapentin $900 \mathrm{mg}$ PO in the preoperative holding area. All patients were given an intake form during their initial consultation with the neurosurgeon. Patients who marked that they were "on chronic and current benzodiazepines or opioids" on this form were considered high risk for pain. The acute pain service was to be made aware of all high-risk pain patients, and they were to receive ketamine $30 \mathrm{mg}$ IV with the induction of anesthesia (Loftus et al. 2010). There were no specific guidelines for intraoperative opioid use. Prior to leaving the recovery room a fentanyl, morphine, or hydromorphone, PCA was 
Table 1 Lumbar spinal fusion ERAS protocol

\begin{tabular}{lll}
\hline Stage & Location & Action \\
\hline Preoperative & $\begin{array}{l}\text { Neurosurgical } \\
\text { clinic visit }\end{array}$ & - 1-2-level lumbar fusion patients \\
& & identified to be included in the project \\
& & - Neurosurgery Spine Booking Checklist \\
completed and surgery scheduled with \\
the comment "lumbar fusion ERP"
\end{tabular}

- Patient given information letter and materials including diabetes education and smoking cessation

- Patients received a "pain questionnaire" and if any patient selects "on chronic and current benzodiazepines or opioids," they will be considered high risk for pain and the acute pain service will be made aware

Booking office - The following appointments are made:

$$
\begin{aligned}
& \text { § Preoperative services } \\
& \text { §OR for surgery } \\
& \text { § Postoperative wound check ( } 14 \\
& \text { days) and surgical ( } 30 \text { days) follow-up }
\end{aligned}
$$

- A surgical packet will be sent to the patient with the following:

$\S$ Cover letter explaining the contents and what to expect at POS and PSA

$\S$ Instructions for taking or stopping medications

$\S$ Directions to pre-operative services and ambulatory surgery unit

$\S$ Postoperative discharge instructions

$\S$ Social support services information

$\S$ Discharge needs assessment form - to be returned pre-operatively

$\S$ Pre-operative pain questionnaire-to be returned pre-operatively

- Assistant will add the lumbar fusion ERP checklist to the surgical packet that is sent to pre-operative services

Preoperative $\quad$ History and physical-required services

Perioperative Ambulatory surgery unit performed by an anesthesiologist, qualified MD, or physician extender

- Required testing includes T\&S, CBC, PT/PTT, INR, UA, and for diagnosed diabetic patients HgbA1C

- HgbA1c of $\geq 9$ will postpone the surgical date by at least 2 months and will be re-evaluated prior to rebooking

- Incentive spirometry, OSA and CPAP education, NPRS education

- Pre-operative antibiotic orderedAncef $2 \mathrm{~g}$ ( $3 \mathrm{~g}$ if $>120 \mathrm{~kg}$ ), Clindamycin $900 \mathrm{mg}$, or Vancomycin $15 \mathrm{mg} / \mathrm{kg}$

- If identified as a "high-risk pain" the "pain liaison" will visit the patient prior
Table 1 Lumbar spinal fusion ERAS protocol (Continued)

\begin{tabular}{ll}
\hline Stage $\quad$ Location & Action \\
\hline & - Acetaminophen $975 \mathrm{mg}$ PO, gabapentin \\
& $900 \mathrm{mg}$ PO prior to OR \\
& - High-risk patients administer $40 \mathrm{mg}$ \\
& aprepitant for PONV \\
OR for surgery & - Antibiotics will be dosed and given \\
& less than $1 \mathrm{~h}$ prior to incision and re- \\
& dosed as appropriate \\
& - All patients regardless of diabetic status \\
& will receive dexamethasone $8 \mathrm{mg}$ IVP
\end{tabular}

- High-risk patients with known chronic pain may receive ketamine $30 \mathrm{mg}$ with induction

- Follow intra-op protocol as prescribed including hourly attending anesthesia to neurosurgeon communication

$\S$ Should include progress of surgery, fluid status, hemodynamics, pressure point evaluations, EBL

PACU

- Assess patient temperature

- All patients receive $P C A$ and methocarbamol $1500 \mathrm{mg}$ PO or IV

- Pain liaison will visit the patient if identified as "high-risk pain"

Postoperative Floor

- Nursing staff will notify neurosurgery if there are any medically necessary deviations from the protocol.

- PT/SW/NS to meet Monday-Friday to review patients' discharge progress

POD\#0 - All patients will receive stool softeners and laxatives delineated in the power plan

- Diet as tolerated

- Continue IVF's until tolerating good oral intake

- Reinforce incentive spirometry

POD\#1 - Discontinue Foley catheter at 0600

- Celecoxib 200 mg Q12H PO, gabapentin $300 \mathrm{mg}$ Q8H PO, and acetaminophen $975 \mathrm{mg}$ Q6H PO to be continued for 1 week

POD\#2

Follow Up Neurosurgical Clinic Visit to OR
- Acute pain assessment for the transition to oral medications

- Mobilize out of bed and reinforce incentive spirometry

- PT evaluation for rehabilitation needs

- SW/Case management evaluation for support services and discharge planning

- If appropriate discontinue surgical drain and continue to mobilize

- Discharge if appropriate

- Follow-up phone call post-discharge day 1

- Wound check visit 2 weeks after discharge 
Table 1 Lumbar spinal fusion ERAS protocol (Continued)

\begin{tabular}{|c|c|c|}
\hline Stage & Location & Action \\
\hline & & $\begin{array}{l}\text { - Regularly scheduled follow-up at } 1 \\
\text { month, } 3 \text { months, } 6 \text { months, and } 1 \text { year }\end{array}$ \\
\hline \multicolumn{3}{|c|}{$\begin{array}{l}\text { The data in italics are the important interventions for measured outcomes } \\
\text { POS preoperative services, PSA presurgical admission, OSA obstructive sleep } \\
\text { apnea, CPAP continuous positive airway pressure, NPRS numeric pain rating } \\
\text { scale, PONV postoperative nausea/vomiting, IVP IV push, EBL estimated blood } \\
\text { loss, PCA patient-controlled analgesia, PT physical therapy, SW social work, } \\
\text { NS neurosurgery }\end{array}$} \\
\hline
\end{tabular}

started, and methocarbamol $1500 \mathrm{mg}$ IV or PO was given to manage pain. Patients also received a non-opioid regimen for 7 days including celecoxib 200 mg Q12H PO, gabapentin $300 \mathrm{mg}$ Q8H PO, and acetaminophen $975 \mathrm{mg}$ Q6H PO (Doleman et al. 2015). To decrease hospital LOS, the postoperative interventions included early physical therapy (PT) and social work involvement on postoperative day 1 with early mobilization. Each patient was contacted the day after discharge by phone and then seen in the office for a 2 -week wound check visit. Following the wound check visit, each patient was scheduled for regular follow-up at 3-, 6-, and 12-month intervals.

\section{Data collection}

The pre-ERAS patients (historical control group) were identified through the electronic medical record (EMR) and included patients who underwent 1-2-level lumbar fusion surgery between October 23, 2013, and September 9, 2015. A transition phase after the ERAS protocol was started lasted from September 10, 2015, to November 5,2015 . During this transition phase, staff and physicians were educated on the protocol and became familiar with its steps to improve compliance. Regular meetings of all ERAS team leads and members were held. The entire ERAS protocol was made available in the EMR to be used as a reference when needed, and reminders were integrated into the intraoperative anesthesia EMR. After the transition phase, post-ERAS patients underwent surgery between November 9, 2015, and May 3, 2017.

All preoperative, intraoperative, and postoperative data were collected from the EMR for both the pre-ERAS and ERAS groups and entered into a database. We followed patients for up to 1 year from their surgical date. This report includes data collected from the preoperative period through patients' first postoperative visit within 30 days of discharge from the hospital (Table 5).

\section{Prespecified quality metrics}

Prespecified quality metrics included the number of case cancelations, the incidence of postoperative nausea and vomiting (PONV), opioid usage, postoperative pain, and length of stay. The protocol planned to use rescheduled cases as a measure to track case cancelations. Length of stay was determined based on a patient's admission time and discharge time as recorded in the EMR for the encounter number that correlated to the surgical admission for lumbar fusion. PCA use and all other analgesic medications used were recorded for postoperative day 0 through postoperative day 3 , at which time it was expected that a majority of patients would be discharged. Medication use at each postoperative visit was also recorded. Patient pain was measured based on an 11-point numerical pain rating scale (NPRS) in which patients rate their pain ranging from 0 (no pain) to 10 (worst imaginable pain). The NPRS has been shown to be effective at showing pain improvement in patients with low back pain when the NPRS shows a difference of greater than 2 points (Childs et al. 2005). The NPRS was measured prior to surgery, each day during their hospital stay, and at each postoperative clinic visit. During this project, each NPRS measurement was multiplied by 10 to create a pain score range of 0 (no pain) to 100 (worst imaginable pain) to simplify the analysis of pain scores.

\section{Statistical methods}

A statistician (co-author LN) performed all statistical analyses. Categorical variables were computed using the Monte Carlo simulations of exact $p$ values from Pearson's chi-squared tests. For continuous variables, $p$ values were computed using the Wilcoxon rank sum test if normality checks using the Shapiro-Wilk test failed. Otherwise, two-sample $t$ tests were used. If variances from pre-ERAS and post-ERAS were found to be unequal using the $F$ test, then the Satterthwaite two-sample $t$ test was used. Otherwise, the pooled two-sample $t$ test was used. As this was a QI project, there was no formal hypothesis testing, nor any formal sample size calculation.

\section{Results \\ Demographics}

Overall, 230 eligible surgical patients were included. There were 123 patients in the pre-ERAS group (23-month period), 11 patients in the transition phase (2-month period), and 96 patients in the post-ERAS group (18-month period). The pre-ERAS and post-ERAS group patients were not significantly different with regard to potential confounders such as demographics and comorbidities except for the rate of obstructive sleep apnea $(4.2 \%$ in the post-ERAS group and $12.9 \%$ in the pre-ERAS group, see Table 2).

Perioperative characteristics were also similar between the two groups (Table 3). Postoperative mobility and complications were not statistically different between the pre-ERAS and post-ERAS groups. 


\section{Protocol compliance}

Compliance with the ERAS bundle was mixed (Table 4). On the day of surgery, post-ERAS patients received oral gabapentin and acetaminophen with 78\% and 81\% compliance rates, respectively. Dexamethasone administered after induction of general anesthesia increased from $4.8 \%$ of pre-ERAS patients to $27 \%$ of post-ERAS patients $(p<0.0001$, Table 3$)$. There was only a small increase in the number of patients receiving ketamine in the post-ERAS group, which was not significant. All patients were to receive $1500 \mathrm{mg}$ methocarbamol and a PCA in the recovery room. The rate of methocarbamol use improved in the post-ERAS group ( $44 \%$ of pre-ERAS versus $62 \%$ in post ERAS groups, $p=0.0137)$. Prior to ERAS, $93 \%$ of patients were already receiving a PCA so the slight increase to $94.8 \%$ was not surprising.

\section{Outcomes}

After the implementation of ERAS, we observed a statistically significant $(p=0.0125)$ decrease in the administration of rescue antiemetics in the recovery room for nausea (40\% pre-ERAS versus $24 \%$ post-ERAS) (Table 4 ). With regard to opioid administration, in the pre-ERAS group, $7 \%$ of patients required a PCA after $24 \mathrm{~h}$, whereas this decreased to $0 \%$ post-ERAS. Long-acting opioids included OxyContin, MSContin, Methadone, or any other opioids that are designated as an extended-release. Short-acting opioids were defined as any opioid not included as an extended-release or long-acting opioid. No significant differences were observed in the number of patients requiring short-acting opioids postoperatively or at the first postoperative visit. However, we observed a benefit with regard to long-acting opioids with lower use at the first postoperative visit after implementation of ERAS (14.6\% pre-ERAS vs. $5.2 \%$ post-ERAS, $p=0.0253$, see Table 5). The percentage of patients receiving anticonvulsants at discharge increased from 22 to $67 \%$ in the pre-ERAS and post-ERAS groups, respectively. This increase was expected since it reflects the use of gabapentin postoperatively as part of the ERAS bundle. The length of stay between the pre-ERAS and post-ERAS groups decreased by $5 \mathrm{~h}$ from 96 to $92 \mathrm{~h}$; however, this did not reach statistical significance $(p=0.1372)$. Postoperative pain scores were similar in both groups. The NPRS at the post-discharge follow-up visit was also not statistically different between the two groups.

\section{Discussion}

Our results did show a small improvement in the incidence of PONV and a decrease in the use of long-acting opioid, but no differences in postoperative pain, short-term opioid use, and length of stay were found.

Patient care often lags behind the most recent evidence-based practice recommendations. The ERAS movement was started to improve efficiency, reduce morbidity, improve patient experience, and decrease cost. Our spine ERAS QI protocol was implemented to improve post-operative patient care and surgical outcomes similar to what has been done with ERAS in other surgical specialties.

There are few reports of ERAS in spine surgery, with most publications focusing on the implications and feasibility of implementing a spine ERAS program (Wainwright et al. 2016; Blackburn et al. 2016; Ali et al. 2018). Blackburn et al. implemented an ERAS bundle for all elective spine surgeries including some lumbar fusions (Blackburn et al. 2016), and the other spinal ERAS projects have investigated endoscopic lumbar fusions and correction of scoliosis (Wang et al. 2017; Gornitzky et al. 2016; Muhly et al. 2016). Based on these other reports, our ERAS protocol was more pragmatic and focus on improving postoperative outcomes by decreasing case cancelations, incidence of PONV, postoperative pain, postoperative opioid usage, and length of hospital stay.

By focusing on improved communication between the clinic staff, surgeons, anesthesiologists, and operating room scheduling staff, we hoped to decrease delays and case cancelations. We attempted to measure case cancelations by determining which lumbar fusions had been rescheduled, but we found that this was unreliable due to case cancelations that occurred for unrelated reasons such as illness and other patient factors. It should be mentioned that the neuroanesthesiologists and neurosurgeons remarked that after the ERAS implementation, patients were better prepared on the day of surgery, and there were fewer delays due to problems with surgical consents, waiting for labs, retrieving missing preoperative evaluations, and medication histories.

Pain control was another focus of the ERAS protocol. Our ERAS protocol included oral non-opioid medications preoperatively to help reduce opioid needs postoperatively. The acute pain service was to be made aware of all high-risk pain patients, and they were to receive ketamine $30 \mathrm{mg}$ IV with the induction of anesthesia. All patients were to receive a PCA postoperatively, and $1500 \mathrm{mg}$ of methocarbamol in the PACU for early pain control. Gabapentin, celecoxib, and acetaminophen were also added to the postoperative pain regimen which is reflected in the increased number of patients on anti-convulsant medications in the postoperative period. A multimodal approach to pain treatment has been shown to decrease postoperative opioid use and decreased time to mobilization in spine surgery (Mathiesen et al. 2013). The Post-ERAS patients showed decreased postoperative opioid use with significantly fewer patients using long-acting opioids postoperatively, and none of the post-ERAS patients required a PCA after $24 \mathrm{~h}$. The ERAS interventions did not change the number of 
Table 2 Demographic and co-morbidities

\begin{tabular}{|c|c|c|c|}
\hline & $\begin{array}{l}\text { Pre-ERAS } \\
(n=123)\end{array}$ & $\begin{array}{l}\text { Post-ERAS } \\
(n=96)\end{array}$ & $\begin{array}{l}{ }^{*} p \\
\text { value }\end{array}$ \\
\hline Number of patients & 123 & 96 & \\
\hline Gender, \# and \% male & $53(43.1 \%)$ & $48(50.0 \%)$ & 0.3395 \\
\hline Age & $60.3(12.9)$ & $61.3(13.3)$ & 0.7308 \\
\hline BMl & $29.7(5.5)$ & $29.7(4.8)$ & 0.7783 \\
\hline Coronary artery disease, \#(\%) & $15(12.2 \%)$ & $10(10.4 \%)$ & 0.8286 \\
\hline Hypertension, \#(\%) & $68(55.3 \%)$ & $50(52.1 \%)$ & 0.6715 \\
\hline Asthma, \#(\%) & $13(10.6 \%)$ & $7(7.3 \%)$ & 0.4834 \\
\hline $\begin{array}{l}\text { Chronic obstructive pulmonary disease, } \\
\#(\%)\end{array}$ & $8(6.5 \%)$ & $7(7.3 \%)$ & 1.0000 \\
\hline $\begin{array}{l}\text { Diabetes mellitus—non-insulin } \\
\text { dependent, } \#(\%)\end{array}$ & $9(7.3 \%)$ & $15(15.6 \%)$ & 0.0794 \\
\hline $\begin{array}{l}\text { Diabetes mellitus-insulin dependent, } \\
\#(\%)\end{array}$ & $4(3.3 \%)$ & $2(2.1 \%)$ & 0.7009 \\
\hline $\begin{array}{l}\text { History of cerebrovascular accident, } \\
\#(\%)\end{array}$ & $4(3.3 \%)$ & $5(5.2 \%)$ & 0.5096 \\
\hline Anxiety, \#(\%) & $22(17.9 \%)$ & $17(17.7 \%)$ & 1.0000 \\
\hline Depression, \#(\%) & $18(14.6 \%)$ & $10(10.4 \%)$ & 0.4078 \\
\hline Kidney disease, \#(\%) & $10(8.1 \%)$ & $4(4.2 \%)$ & 0.2775 \\
\hline Liver disease, \#(\%) & & $2(2.1 \%)$ & 0.1926 \\
\hline Obstructive sleep apnea, \#(\%) & $16(13.0 \%)$ & $4(4.2 \%)$ & 0.0326 \\
\hline Alcohol abuse, \#(\%) & $2(1.6 \%)$ & & 0.5024 \\
\hline \multicolumn{4}{|l|}{ Tobacco abuse, \#(\%) } \\
\hline - Yes, NOT within the last 6 months & $39(31.7 \%)$ & $41(42.7 \%)$ & 0.1199 \\
\hline - Yes, within the last 6 months & $25(20.3 \%)$ & $15(15.6 \%)$ & 0.3850 \\
\hline \multicolumn{4}{|l|}{ Substance abuse, \#(\%) } \\
\hline - Yes, NOT within the last 6 months & $2(1.6 \%)$ & $4(4.2 \%)$ & 0.4307 \\
\hline - Yes, within the last 6 months & $3(2.4 \%)$ & $2(2.1 \%)$ & 1.0000 \\
\hline ASA PS class $\geq 3$ & $63(51.2 \%)$ & $50(52.1 \%)$ & 1.0000 \\
\hline \multicolumn{4}{|l|}{ Non-surgical treatments utilized } \\
\hline • Physical therapy & $51(41.5 \%)$ & $23(24.0 \%)$ & 0.0104 \\
\hline - Acupuncture & $17(13.8 \%)$ & $8(8.3 \%)$ & 0.2928 \\
\hline - Chiropractic & $27(22.0 \%)$ & $14(14.6 \%)$ & 0.2222 \\
\hline - Epidural or facet injections & $78(63.4 \%)$ & $51(53.1 \%)$ & 0.1310 \\
\hline \multicolumn{4}{|l|}{ Preoperative pain medication (last 30 days) } \\
\hline - NSAIDs & $76(61.8 \%)$ & $48(50.0 \%)$ & 0.0992 \\
\hline $\begin{array}{l}\text { - Opioids, short-acting (immediate- } \\
\text { release) }\end{array}$ & $57(46.3 \%)$ & $47(49.0 \%)$ & 0.7852 \\
\hline $\begin{array}{l}\text { - Opioids, long-acting (extended-re- } \\
\text { lease, e.g., OxyContin, MSContin, } \\
\text { Methadone) }\end{array}$ & $4(3.3 \%)$ & $2(2.1 \%)$ & 0.7021 \\
\hline - Anticonvulsants & $30(24.4 \%)$ & $29(30.2 \%)$ & 0.3720 \\
\hline - Antidepressants & $31(25.2 \%)$ & $29(30.2 \%)$ & 0.4464 \\
\hline - Benzodiazepines & $18(14.6 \%)$ & $12(12.5 \%)$ & 0.6964 \\
\hline - Muscle relaxants & $24(19.5 \%)$ & $11(11.5 \%)$ & 0.1350 \\
\hline - Acetaminophen & $42(34.1 \%)$ & 34 (35.4\%) & 0.8826 \\
\hline
\end{tabular}

Table 3 Perioperative data

\begin{tabular}{|c|c|c|c|}
\hline & $\begin{array}{l}\text { Pre-ERAS }(n= \\
123)\end{array}$ & $\begin{array}{l}\text { Post-ERAS } \\
(n=96)\end{array}$ & $\begin{array}{l}{ }^{*} p \\
\text { value }\end{array}$ \\
\hline Preoperative pain score (NPRS) & $63.7(24.7)$ & $69.5(22.3)$ & 0.0969 \\
\hline \multicolumn{4}{|l|}{$\begin{array}{l}\text { Pre-operative medications given } \\
\text { orally on the day of surgery prior } \\
\text { to OR }\end{array}$} \\
\hline • Gabapentin 900 mg & $4(3.3 \%)$ & 75 (78.1\%) & $<.0001$ \\
\hline - Acetaminophen 975 mg & $3(2.4 \%)$ & $78(81.3 \%)$ & $<.0001$ \\
\hline - Aprepitant 40 mg & $1(0.8 \%)$ & $2(2.1 \%)$ & 0.5786 \\
\hline \multicolumn{4}{|l|}{ Number of levels fused } \\
\hline$\cdot 1$ & $71(57.7 \%)$ & $54(56.3 \%)$ & 0.8906 \\
\hline$\cdot 2$ & $52(42.3 \%)$ & $42(43.8 \%)$ & 0.8879 \\
\hline Estimated blood loss > $300 \mathrm{~mL}$ & $24(19.5 \%)$ & $33(34.4 \%)$ & 0.0152 \\
\hline $\begin{array}{l}\text { Blood products given in } O R \text {, } \\
\#(\%)\end{array}$ & $1(0.8 \%)$ & $1(1.0 \%)$ & 1.0000 \\
\hline Colloid given in OR & $13(10.6 \%)$ & $8(8.3 \%)$ & 0.6480 \\
\hline Volume of crystalloid (mL) & 2070.9 (736.2) & $1761.5(739.2)$ & 0.0003 \\
\hline Drain placed & $118(95.9 \%)$ & $96(100.0 \%)$ & 0.0720 \\
\hline $\begin{array}{l}\text { Dexamethasone } 8 \mathrm{mg} \mathrm{IV} \\
\text { intraoperative }\end{array}$ & $6(4.9 \%)$ & $26(27.1 \%)$ & $<.0001$ \\
\hline Ketamine $30 \mathrm{mg}$ on induction & $2(1.6 \%)$ & $5(5.2 \%)$ & 0.2497 \\
\hline Duration of surgery (min) & $184.7(85.4)$ & $212.2(140.4)$ & 0.3093 \\
\hline Intraoperative dural tear & $4(3.3 \%)$ & $1(1.0 \%)$ & 0.3959 \\
\hline
\end{tabular}

patients using short-acting opioids in the postoperative period, but it should be recognized that this was a qualitative measurement and the morphine equivalents of all opioids used were not collected as part of the data. Despite the decrease in long-acting opioid use, there was no difference in pain scores between the pre-ERAS and post-ERAS groups.

PONV is often a problem in patients following surgery. In addition to the regular antiemetic regimen that is given to most patients including intraoperative ondansetron, the ERAS protocol included dexamethasone $8 \mathrm{mg}$ after induction and oral aprepitant for high-risk patients preoperatively. Despite a small increase of 4 to $27 \%$ compliance between the pre- and post-ERAS patients receiving dexamethasone intraoperatively and only 2 patients receiving aprepitant in the post ERAS group, there was still a significant decrease in the patients requiring a rescue antiemetic in the recovery room. With improved compliance, this may improve further in the future.

Decreasing LOS helps to reduce costs and is an important outcome measure in many enhanced recovery protocols (Gustafsson et al. 2013; Nygren et al. 2013; Lassen et al. 2013). There are many factors that affect LOS. Preoperative comorbidities are not the sole contributor to LOS, and the most significant factors that prolong LOS are postoperative events such as bleeding, drains, late mobilization, and delayed discharge to 
Table 4 Postoperative data

\begin{tabular}{|c|c|c|c|}
\hline & $\begin{array}{l}\text { Pre-ERAS } \\
(n=123)\end{array}$ & $\begin{array}{l}\text { Post-ERAS } \\
(n=96)\end{array}$ & $\begin{array}{l}{ }^{*} p \\
\text { value }\end{array}$ \\
\hline PACU temperature on arrival & $35.8(5.1)$ & $36.5(0.4)$ & 0.4443 \\
\hline Antiemetic given in PACU & 49 (39.8\%) & $23(24.0 \%)$ & 0.0125 \\
\hline $\begin{array}{l}\text { Methocarbamol } 1500 \mathrm{mg} \text { given in } \\
\text { PACU }\end{array}$ & $54(43.9 \%)$ & $59(61.5 \%)$ & 0.0137 \\
\hline NPRS before PACU discharge & $50.0(22.3)$ & $43.7(23.9)$ & 0.0925 \\
\hline Total patients with PCA & $\begin{array}{l}115 \\
(93.5 \%)\end{array}$ & $91(94.8 \%)$ & 0.7803 \\
\hline - Morphine, \# (\% of total PCA) & $56(45.5 \%)$ & $38(39.6 \%)$ & 0.4209 \\
\hline - Hydromorphone, \# (\% of total PCA) & $55(44.7 \%)$ & $51(53.1 \%)$ & 0.2236 \\
\hline - Fentanyl, \# (\% of total PCA) & $5(4.1 \%)$ & $2(2.1 \%)$ & 0.4634 \\
\hline PCA duration $\geq 24 \mathrm{~h}$ & $9(7.3 \%)$ & & 0.0116 \\
\hline Urinary catheter duration $\geq 24 \mathrm{~h}$ & $42(34.1 \%)$ & $30(31.3 \%)$ & 0.6565 \\
\hline \multicolumn{4}{|l|}{ Day of surgery medications given } \\
\hline - NSAIDS & $4(3.3 \%)$ & $10(10.4 \%)$ & 0.0533 \\
\hline $\begin{array}{l}\text { - Opioids, short-acting } \\
\text { (immediate-release) }\end{array}$ & $\begin{array}{l}123 \\
(100.0 \%)\end{array}$ & $95(99.0 \%)$ & 0.4343 \\
\hline $\begin{array}{l}\text { - Opioids, long-acting (extended-re- } \\
\text { lease, e.g., OxyContin, MSContin, } \\
\text { Methadone) }\end{array}$ & $6(4.9 \%)$ & & 0.0345 \\
\hline - Anticonvulsants & $22(17.9 \%)$ & $55(57.3 \%)$ & $<.0001$ \\
\hline - Antidepressants & $8(6.5 \%)$ & $5(5.2 \%)$ & 0.7788 \\
\hline • Benzodiazepines & 19 (15.4\%) & $16(16.7 \%)$ & 0.8518 \\
\hline - Muscle relaxants & 97 (78.9\%) & $83(86.5 \%)$ & 0.1603 \\
\hline - Acetaminophen & $62(50.4 \%)$ & $45(46.9 \%)$ & 0.6868 \\
\hline \multicolumn{4}{|l|}{ Postoperative day \#1 NPRS pain scores } \\
\hline - Minimum pain score & $10.8(16.0)$ & $15.3(17.0)$ & 0.0249 \\
\hline - Maximum pain score & $75.0(19.4)$ & $75.8(18.4)$ & 0.791 \\
\hline \multicolumn{4}{|l|}{ Postoperative day \#1 medications given } \\
\hline - NSAIDs & $6(4.9 \%)$ & $11(11.5 \%)$ & 0.0777 \\
\hline $\begin{array}{l}\text { - Opioids, short-acting (immediate- } \\
\text { release) }\end{array}$ & $\begin{array}{l}119 \\
(96.7 \%)\end{array}$ & $92(95.8 \%)$ & 1.0000 \\
\hline $\begin{array}{l}\text { - Opioids, long-acting (extended-re- } \\
\text { lease, e.g., OxyContin, MSContin, } \\
\text { Methadone) }\end{array}$ & $23(18.7 \%)$ & $5(5.2 \%)$ & 0.0028 \\
\hline - Anticonvulsants & $30(24.4 \%)$ & $71(74.0 \%)$ & $<.0001$ \\
\hline - Antidepressants & $20(16.3 \%)$ & $10(10.4 \%)$ & 0.2312 \\
\hline • Benzodiazepines & 35 (28.5\%) & $33(34.4 \%)$ & 0.3779 \\
\hline - Muscle relaxants & $\begin{array}{l}113 \\
(91.9 \%)\end{array}$ & $87(90.6 \%)$ & 0.8096 \\
\hline - Acetaminophen & $98(79.7 \%)$ & $86(89.6 \%)$ & 0.0620 \\
\hline \multicolumn{4}{|l|}{ Postoperative day \#2 NPRS pain scores } \\
\hline - Minimum pain score & $6.9(12.1)$ & $15.3(18.9)$ & 0.0003 \\
\hline - Maximum pain score & $73.5(18.9)$ & $74.8(19.7)$ & 0.5559 \\
\hline \multicolumn{4}{|c|}{ Postoperative day \#2 medications given (for patients not yet discharged) } \\
\hline$\cdot$ NSAIDS & $7(5.7 \%)$ & $9(9.4 \%)$ & 0.4352 \\
\hline $\begin{array}{l}\text { - Opioids, short-acting (immediate- } \\
\text { release) }\end{array}$ & $\begin{array}{l}111 \\
(90.2 \%)\end{array}$ & $83(86.5 \%)$ & 0.4063 \\
\hline
\end{tabular}

Table 4 Postoperative data (Continued)

\begin{tabular}{llll}
\hline & $\begin{array}{l}\text { Pre-ERAS } \\
(n=123)\end{array}$ & $\begin{array}{l}\text { Post-ERAS } \\
(n=96)\end{array}$ & $\begin{array}{l}{ }^{*} p \\
\text { value }\end{array}$ \\
\hline $\begin{array}{l}\text { - Opioids, long acting } \\
\text { (extended-release, e.g., }\end{array}$ & $28(22.8 \%)$ & $5(5.2 \%)$ & 0.0002 \\
$\begin{array}{l}\text { OxyContin, MSContin, } \\
\text { Methadone) }\end{array}$ & & & \\
- Anticonvulsants & $30(24.4 \%)$ & $66(68.8 \%)$ & $<.0001$ \\
- Antidepressants & $22(17.9 \%)$ & $10(10.4 \%)$ & 0.1311 \\
- Benzodiazepines & $34(27.6 \%)$ & $29(30.2 \%)$ & 0.7643 \\
- Muscle relaxants & 112 & $86(89.6 \%)$ & 0.8108 \\
- Acetaminophen & $(91.1 \%)$ & & \\
Postoperative day \#3 & $94(76.4 \%)$ & $82(85.4 \%)$ & 0.1236 \\
NPRS pain scores & & & \\
- Minimum pain score & & & \\
- Maximum pain score & $8.9(14.0)$ & $15.6(19.1)$ & 0.0158 \\
& $69.1(22.6)$ & $68.0(21.4)$ & 0.499
\end{tabular}

Postoperative day \#3

medications given

(for patients not yet

discharged)

- NSAIDs

- Opioids, short-acting (immediate-release)

- Opioids, long-acting (extended-release, e.g.,

OxyContin, MSContin,

Methadone)

- Anticonvulsants

$29(23.6 \%) \quad 52(54.2 \%) \quad 0.0001$

- Antidepressants

- Benzodiazepines

- Muscle relaxants

- Acetaminophen

$\begin{array}{lll}7(5.7 \%) & 7(7.3 \%) & 0.7846 \\ 91(74.0 \%) & 65(67.7 \%) & 0.3713\end{array}$

$22(17.9 \%) \quad 4(4.2 \%) \quad 0.0020$

Postoperative day patient out of bed

Postoperative day patient seen by PT

$16(13.0 \%) \quad 6(6.3 \%) \quad 0.1114$

$24(19.5 \%) \quad 18(18.8 \%) \quad 1.0000$

$97(78.9 \%) \quad 66(68.8 \%) \quad 0.1208$

$63(51.2 \%) \quad 54(56.3 \%) \quad 0.4919$

$2.2(0.4) \quad 2.3(0.6) \quad 0.4102$

$2.2(0.4) \quad 2.2(0.5) \quad 0.6943$

Postoperative complications

$\begin{array}{llll}\text { - Reintubation } & 2(1.6 \%) & 1(1.0 \%) & 1.0000\end{array}$

$\cdot \mathrm{Ml}$

- Death

$\begin{array}{lll}\text { - Rapid response } \quad 2(2.1 \%) & 0.1928\end{array}$

- Other

$4(4.2 \%) \quad 0.0355$

Length of stay (hours)

$96.2(32.0) \quad 92.3(36.9) \quad 0.1372$

rehabilitation facilities (Gruskay et al. 2015). To help patients get out of bed on postoperative day 1 , the protocol required urinary catheters to be removed in the morning after surgery, but compliance was poor with no change between the two groups. The protocol also included early involvement of social work to identify any potential discharge needs and to have physical therapy get all patients out of bed on postoperative day 1 (Kanaan et al. 
Table 5 Postoperative follow-up within 30 days of discharge

\begin{tabular}{llll}
\hline & $\begin{array}{l}\text { Pre-ERAS } \\
(n=123)\end{array}$ & $\begin{array}{l}\text { Post-ERAS } \\
(n=96)\end{array}$ & $\begin{array}{l}{ }^{*} p \\
\text { value }\end{array}$ \\
\hline $\begin{array}{l}\text { Patient contacted 1 day after } \\
\text { discharge }\end{array}$ & $4(3.3 \%)$ & $9(9.4 \%)$ & 0.0803 \\
$\begin{array}{l}\text { Pain at postoperative wound visit } \\
\text { (NPRS) }\end{array}$ & $45.6(25.3)$ & $48.9(26.0)$ & 0.3575 \\
$\begin{array}{l}\text { Medications used at postoperative } \\
\text { wound visit }\end{array}$ & & & \\
- NSAIDs & $32(26.0 \%)$ & $24(25.0 \%)$ & 0.8728 \\
- Opioids, short-acting (immedi- & $100(81.3 \%)$ & $80(83.3 \%)$ & 0.7247 \\
$\begin{array}{l}\text { ate-release) } \\
\text { - Opioids, long-acting (extended- } \\
\text { release, e.g., OxyContin, MSContin, }\end{array}$ & $18(14.6 \%)$ & $5(5.2 \%)$ & 0.0253 \\
$\begin{array}{l}\text { Methadone) } \\
\text { - Anticonvulsants }\end{array}$ & $27(22.0 \%)$ & $64(66.7 \%)$ & $<.0001$ \\
- Antidepressants & $25(20.3 \%)$ & $22(22.9 \%)$ & 0.7416 \\
- Benzodiazepines & $27(22.0 \%)$ & $23(24.0 \%)$ & 0.7449 \\
- Muscle relaxants & $97(78.9 \%)$ & $63(65.6 \%)$ & 0.0348 \\
- Acetaminophen & $49(39.8 \%)$ & $48(50.0 \%)$ & 0.1675 \\
Signs of infection present & $2(1.6 \%)$ & $2(2.1 \%)$ & 1.0000 \\
\hline
\end{tabular}

2015). Social work and physical therapy are both very busy services in our institution, and involving them early was difficult due to time constraints and limited coverage on the weekends. The average time for physical therapy to see the pre-ERAS and post-ERAS patients was similar at 2 days postoperatively. We did not observe any significant reduction in LOS, which may be related to poor compliance of protocol adherence. Hence, we were unable to determine whether the ERAS protocol elements have any significant effect on LOS.

New ERAS protocols not only focus on specific perioperative interventions by surgeons and anesthesiologists, but they have expanded to focus on preoperative patient education, building more effective team care models, improving patient satisfaction, and improved discharge planning. Our ERAS protocol focused on some of these expanded ideas to improve patient education and interdepartmental teamwork. Preoperative patient education has become an important part of improving patient care perioperatively. Educating patients about expectations postoperatively can improve postoperative patient satisfaction and decrease patient morbidities and pain scores after lumbar surgery (Archer et al. 2011). Smoking cessation is also an important issue included in the preoperative patient education. Smokers experience a higher rate of postoperative pseudarthrosis and infection after spinal fusion. Smoking cessation can help decrease these complications depending on the timing of smoking cessation (Jackson 2nd and Devine 2016). Smoking cessation was reiterated at both the neurosurgery clinic visits and preoperative services visit in addition to printed literature that patients received. Information regarding fasting guidelines and day of surgery medication use has also been an issue for some patients in the past at our institution, so education on these topics was provided to patients verbally and in printed handouts prior to surgery.

Some of the limitations of this study include a single institution, and it was a non-randomized, non-blinded project with historical patients identified from a record search of the EMR. Compliance from nursing, surgical, and anesthesia teams in following the protocol was also suboptimal which is reflected in the intervention compliance. There are many barriers to implementing ERAS protocols such as ineffective communication among team members, patient non-compliance, staff turnover with the need for continued education, and physician and staff non-compliance. This is not unique to this ERAS project and has been shown in other studies as well (Kahokehr et al. 2009; Pedziwiatr et al. 2015). Another limitation of this study was that pain medication use was measured qualitatively and not quantitatively. The use of morphine equivalents would have provided a better comparison of narcotic pain use. It is also worth mentioning that improving communication in the perioperative period made all care providers aware of the ongoing QA project and may lead to the Hawthorne effect. Providers involved in care of the ERAS patients may have been more particular about charting and the care they provided, because they were aware that data was being collected. This change in behavior by itself may result in better outcomes.

Despite the limitations, we were able to successfully implement the spine ERAS protocol at our institution with improvement in some aspects of patient outcomes. The care of the lumbar fusion patients intraoperatively has become more standardized, and perioperative teams have become more familiar with the protocol and compliance has continued to improve. This early data showing decreases in PONV and long-acting opioid use is also promising as we continue to move forward with this project. This study also demonstrates the areas where implementations are most challenging for ERAS QI projects. Future studies can focus on these areas for further compliance improvement.

\section{Conclusions}

In our study, the ERAS protocol was associated with a decrease in the incidence of postoperative nausea, a shorter duration of opioid use and a decrease in long-acting opioid use. It also improved communication among the perioperative team and improvement in patient education preoperatively. However, it did not result 
in clinically significant reductions in LOS, decreased postoperative pain scores, or decreased short-acting opioid use. Moving forward, we have implemented steps and education to improve adherence to the protocol, in particular improving the timeliness of postoperative physical therapy and social work assessment of patients.

\section{Abbreviations}

ASA PS: American Society of Anesthesiologists physical status;

CPAP: Continuous positive airway pressure; EBL: Estimated blood loss;

EMR: Electronic medical record; ERAS: Enhanced recovery after surgery; ERP: Enhanced recovery protocol; IV: Intravenous; IVP: Intravenous push; LBP: Low back pain; LOS: Length of stay; NPRS: Numerical pain rating scale; NS: Neurosurgery; NSAID: Non-steroidal anti-inflammatory drug: OR: Operating room; OSA: Obstructive sleep apnea; PACU: Post-anesthesia care unit; PCA: Patient-controlled analgesia; PO: Per os; PONV: Postoperative nausea and vomiting; POS: Preoperative services; PSA: Presurgical admission; PT: Physical therapy; QI: Quality improvement; SW: Social work

\section{Funding}

Funding for data analysis was provided by the Stony Brook University department of anesthesiology.

\section{Availability of data and materials}

All data generated or analyzed during this study are included in this published article.

\section{Authors' contributions}

JS was involved in the project implementation, data collection, data entry, and data interpretation and a significant contributor in writing the manuscript. SP contributed to project planning, project implementation, ERAS protocol training of staff, data collection, and data interpretation and authoring the manuscript. CC was a major contributor in communication between departments and various offices, and she also played a large role in project planning, data collection, and implementation of the protocol. RD was involved in the project planning and implementation. LN performed the data analysis. KS was a major contributor to the data entry. TG played a role in guiding the project implementation and editing manuscript. EBG played a role in overseeing the project implementation, data interpretation, and authoring manuscript. All authors read and approved the final manuscript.

\section{Ethics approval and consent to participate}

This project was approved by a Stony Brook Medical Center Quality Improvement board to proceed as outlined above.

\section{Consent for publication}

\section{Not applicable}

\section{Competing interests}

The authors declare that they have no competing interests.

\section{Publisher's Note}

Springer Nature remains neutral with regard to jurisdictional claims in published maps and institutional affiliations.

\section{Author details}

${ }^{1}$ Department of Anesthesiology, Stony Brook University Medical Center, 101 Nicolls Rd, Stony Brook, NY 11794, USA. ²Department of Neurosurgery, Stony Brook University Medical Center, 101 Nicolls Rd, Stony Brook, NY 11794, USA. ${ }^{3}$ Department of Applied Mathematics and Statistics, Stony Brook University, 100 Nicolls Rd, Stony Brook, NY 11794, USA.

Received: 11 February 2019 Accepted: 29 April 2019

Published online: 28 May 2019

\section{References}

Ali ZS, Ma TS, Ozturk AK, Malhotra NR, Schuster JM, Marcotte PJ, et al. Pre-optimization of spinal surgery patients: development of a neurosurgical enhanced recovery after surgery (ERAS) protocol. Clin Neurol Neurosurg. 2018;164:142-53.
Apfel CC, Heidrich FM, Jukar-Rao S, Jalota L, Hornuss C, Whelan RP, Zhang K, Cakmakkaya OS. Evidence-based analysis of risk factors for postoperative nausea and vomiting. Br J Anaesth. 2012;109 (5):742-753.

Archer KR, Wegener ST, Seebach C, Song Y, Skolasky RL, Thornton C, et al. The effect of fear of movement beliefs on pain and disability after surgery for lumbar and cervical degenerative conditions. Spine (Phila Pa 1976). 2011; 36(19):1554-62.

Blackburn JMP, Leung YL, Walburn M. An enhanced recovery program for elective spinal surgery patients. JCOM. 2016;23(10):462-9.

Childs JD, Piva SR, Fritz JM. Responsiveness of the numeric pain rating scale in patients with low back pain. Spine (Phila Pa 1976). 2005;30(11):1331-4.

Dagenais S, Caro J, Haldeman S. A systematic review of low back pain cost of illness studies in the United States and internationally. Spine J. 2008;8(1):8-20.

Daneshmand S, Ahmadi H, Schuckman AK, Mitra AP, Cai J, Miranda G, et al. Enhanced recovery protocol after radical cystectomy for bladder cancer. J Urol. 2014;192(1):50-5.

Deyo RA, Weinstein JN. Low back pain. N Engl J Med. 2001;344(5):363-70.

Doleman B, Heinink TP, Read DJ, Faleiro RJ, Lund JN, Williams JP. A systematic review and meta-regression analysis of prophylactic gabapentin for postoperative pain. Anaesthesia. 2015;70(10):1186-204.

Gornitzky AL, Flynn JM, Muhly WT, Sankar WN. A rapid recovery pathway for adolescent idiopathic scoliosis that improves pain control and reduces time to inpatient recovery after posterior spinal fusion. Spine Deform. 2016:4(4):288-95.

Gruskay JA, Fu M, Bohl DD, Webb ML, Grauer JN. Factors affecting length of stay after elective posterior lumbar spine surgery: a multivariate analysis. Spine J. 2015;15(6):1188-95.

Gustafsson UO, Scott MJ, Schwenk W, Demartines N, Roulin D, Francis N, et al. Guidelines for perioperative care in elective colonic surgery: enhanced recovery after surgery (ERAS ${ }^{\odot}$ ) society recommendations. World J Surg. 2013;37(2):259-84

Jackson KL 2nd, Devine JG. The effects of smoking and smoking cessation on spine surgery: a systematic review of the literature. Global Spine J. 2016;6(7):695-701.

Kahokehr A, Sammour T, Zargar-Shoshtari K, Thompson L, Hill AG. Implementation of ERAS and how to overcome the barriers. Int I Surg. 2009;7(1):16-9.

Kanaan SF, Waitman LR, Yeh HW, Arnold PM, Burton DC, Sharma NK. Structural equation model analysis of the length-of-hospital stay after lumbar spine surgery. Spine J. 2015;15(4):612-21.

Kehlet $\mathrm{H}$. Multimodal approach to control postoperative pathophysiology and rehabilitation. Br J Anaesth. 1997:78(5):606-17.

Lassen K, Coolsen MM, Slim K, Carli F, de Aguilar-Nascimento JE, Schafer M, et al. Guidelines for perioperative care for pancreaticoduodenectomy: enhanced recovery after surgery (ERAS ${ }^{\oplus}$ ) society recommendations. World J Surg. 2013;37(2):240-58.

Loftus RW, Yeager MP, Clark JA, Brown JR, Abdu WA, Sengupta DK, et al. Intraoperative ketamine reduces perioperative opiate consumption in opiatedependent patients with chronic back pain undergoing back surgery. Anesthesiology. 2010;113(3):639-46.

Mathiesen O, Dahl B, Thomsen BA, Kitter B, Sonne N, Dahl JB, et al. A comprehensive multimodal pain treatment reduces opioid consumption after multilevel spine surgery. Eur Spine J. 2013;22(9):2089-96.

Muhly WT, Sankar WN, Ryan K, Norton A, Maxwell LG, DiMaggio T, et al. Rapid recovery pathway after spinal fusion for idiopathic scoliosis. Pediatrics. 2016; 137(4):E20151568-e20151568.

Nygren J, Thacker J, Carli F, Fearon KC, Norderval S, Lobo DN, et al. Guidelines for perioperative care in elective rectal/pelvic surgery: enhanced recovery after surgery (ERAS ${ }^{\circledR}$ ) society recommendations. World J Surg. 2013;37(2):285-305.

Pedziwiatr M, Kisialeuski M, Wierdak M, Stanek M, Natkaniec M, Matlok M, et al. Early implementation of enhanced recovery after surgery (ERAS(R)) protocol - compliance improves outcomes: a prospective cohort study. Int J Surg. 2015;21:75-81.

Proietti L, Scaramuzzo L, Schiro GR, Sessa S, Logroscino CA. Complications in lumbar spine surgery: a retrospective analysis. Indian J Orthop. 2013;47(4):340-5.

Wainwright TW, Immins T, Middleton RG. Enhanced recovery after surgery (ERAS) and its applicability for major spine surgery. Best Pract Res Clin Anaesthesiol. 2016;30(1):91-102.

Wang MY, Chang PY, Grossman J. Development of an enhanced recovery after surgery (ERAS) approach for lumbar spinal fusion. J Neurosurg Spine. 2017;26(4):411-8. 